\title{
Das Sterben neu denken
}

\section{Adrian Ritter}

Freier Journalist

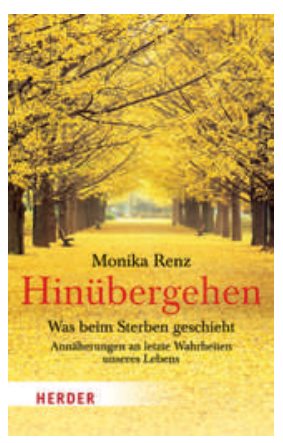

Monika Renz Hinübergehen. Was beim Sterben geschieht

Annäherungen an letzte Wahrheiten unseres Lebens Freiburg im Breisgau: Herder; 2016. 176 Seiten. $11.60 \mathrm{CHF}$, E-Book: $8.90 \mathrm{CHF}$ ISBN: 978-3-45106788-4

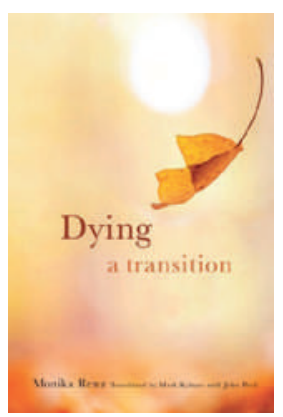

Monika Renz Dying: a transition

New York: Columbia University Press, 2015. 176 Seiten. 53.30 CHF. ISBN: 978-0-23117088-8

\author{
Monika Renz ist Sterbebegleiterin und Sterbeforscherin am Kantonsspital St. Gallen. \\ In zwei neuen Publikationen verdichtet sie ihre Erfahrungen zu einer These: Beim \\ Sterben überschreitet der Mensch eine Bewusstseinsschwelle.
}

Was erleben Sterbende? Diese Frage beschäftigt die Psychotherapeutin, Musiktherapeutin und Theologin Monika Renz schon lange. Seit 1998 ist sie Leiterin der Psychoonkologie am Kantonsspital St. Gallen. Sie und ihr Team bieten psychotherapeutische Gespräche, musiktherapeutische Entspannungen, Sterbebegleitung und wo erwünscht - spirituelle Begleitung. In ihrem Buch Hinübergehen und der englischsprachigen Publikation Dying: a transition fasst sie ihre Erfahrungen mit über 1000 Sterbenden und 680 Patienten zusammen.

Sterbende scheinen einmal oder mehrfach eine innere Bewusstseinsschwelle zu überschreiten, so die Quintessenz von Monika Renz. Sie beschreibt drei Phasen, durch die sich Sterbende bewegen. In der Phase des «Davor» rückt der Tod näher - bisweilen wie eine heranrollende Lawine oder ein gähnender Drachenschlund. Aber auch intensive Begegnungen mit Angehörigen gehören zu dieser Phase. In der zweiten Phase des «Hindurch» treten Sterbende über diese Schwelle. Hier geschieht das Loslassen, wobei manche Sterbende «Urängste» wie apokalyptische Dimensionen des Verschlingenden und Untergehenden durchleben. Wo die Sprache fehlt, seien oft nur körperliche Reaktionen wie Zittern und Schwitzen sichtbar, beschreibt Renz. In der dritten Phase des "Danach» sei die Zeit der Kämpfe durchgestanden. Der Sterbende erlebe einen anderen Bewusstseinszustand - einen Übergang vom Ich zum Sein. Das Ich als Subjekt aller Wahrnehmung und allen Denkens werde unwesentlich. Dimensionen von Raum und Zeit verändern sich - Erfahrungen von Gleichzeitigkeit, Zeitlosigkeit und der Überwindung aller räumlichen Begrenzung treten auf. Viele Sterbende werden in dieser Phase friedlich, beschreibt Renz.

Die Dimension des sich verändernden Bewusstseins werde bisher selbst von der «Spiritual Care» vernachlässigt, indem auch diese auf die bewussten Bedürfnisse Sterbender fokussiere, schreibt Renz. Sie fordert zusätzlich zur bedürfnisorientierten Palliativmedizin und -pflege eine Sterbebegleitung, welche die darunterliegende archetypische Ebene und deren Symbolik einschliesst. Bei Sterbenden von Delir zu sprechen, treffe den Sachverhalt nicht, ihre Symbolsprache folge Gesetzmässigkeiten - Symbole stehen für ein Thema, einen Wandlungsdruck. Wenn ein Patient etwa Spinnweben sehe, spreche sie mit ihm nicht über den Putzplan im Spital, sondern versuche zu ergründen, ob es dem Patienten vielleicht um ein Putzen im SeelischGeistigen gehe. Ein Kapitel des Buches widmet die Autorin häufigen Metaphern im Erleben Sterbender, wobei sie zur Interpretation unter anderem die Traumdeutung nach C.G. Jung, die Bibel und Märchen heranzieht.

Renz ist überzeugt, dass das Wissen um die Phasen in der Erfahrung Sterbender hilft, die schwierigen $\mathrm{Zu}$ stände im «Hindurch» als Durchgangsrealitäten zu ertragen. Im Abtauchen in bewusstseinsferne Zustände verlieren sich selbst Schmerzen und das Empfinden für Leiden. Sterben ganz ohne Leiden gebe es allerdings nicht: «Es gibt aber auch kein Sterben ohne Mysterium, ohne Prozess ins Unbekannte, ins Geheimnis hinein.» Die Begleitung von Sterbenden erfordere ein Hinhören und Verstehen-Versuchen, was in ihnen vor sich geht. Monika Renz findet dabei bisweilen am Patientenbett deutliche Worte. «Springen Sie, wagen Sie es ..., es wird schön", forderte sie etwa Sterbende auf, wenn diese stundenlang im Kampf verstrickt waren. Das «schön» spielt dabei nicht auf ein Jenseits an, sondern auf die Phase des «Danach».

Gleichzeitig formuliert Renz in ihrem Buch vorsichtig und ist sich der Manipulationsgefahr durch das Interpretieren bewusst. Sich selbst versteht die Autorin als "offene religiöse Person und praktizierende Christin». Geprägt worden sei sie zudem in jungen Jahren durch eigene Krankheit und später durch Unfälle, wobei sie nahtodähnliche Erfahrungen machte.

In der Begleitung eines Patienten dürfe es nicht um eine Weltanschauung gehen, so Renz, sondern nur um den Sterbenden als Person. "Aller Antwortversuch bleibt Hilfestellung und als solche Leihgabe zum Annehmen oder Verwerfen.» Die Lektüre der beiden Bücher ist berührend. Sie regt zum Nachdenken über die eigenen Vorstellungen vom Sterben an - und sensibilisiert für einen bewussteren Umgang mit sterbenden Menschen. 